\section{E-values Generated from Substrate Dry-down Models as a Physical Property Measurement for Evaluating and Classifying Wetness of Root Substrates}

\author{
Michael R. Evans ${ }^{1,3}$ \\ Department of Horticulture, 318 Plant Sciences Building, University of \\ Arkansas, Fayetteville, AR 72701 \\ Giampaolo Zanin \\ Department of Environmental Agronomy and Crop Science, University of \\ Padova, Viale dell'Università 16, 35020 Legnaro (PD), Italy
}

Todd J. Cavins ${ }^{2}$

Sun Gro Horticulture, 1213 Fairway Drive, Stillwater, OK 74074

Additional index words. growing media, root media, physical properties, water-holding capacity, wetness

\begin{abstract}
Water-holding capacity represents the volume of water retained by a substrate after a saturating irrigation and drainage, and it is often referred to as container capacity. However, water-holding capacity is a time-specific measurement that is limited to the status of the substrate immediately after saturation and drainage. It does not provide information regarding how quickly water is lost from the substrate, the substrate water status over time, or the irrigation frequency required for a substrate under specific conditions. A new procedure was developed that generated a single numeric value that described the wetness of a substrate and in so doing took into account the substrate's water-holding capacity and drying rate. This value was referred to as an E-value. For substrates included in this study, E-values ranged from a low of 6 for parboiled fresh rice hulls (PBH) to a high of 93 for the commercial substrate Metro Mix 360. The procedure was shown to generate E-values that were as would be expected for the evaluated substrates and also ranked the substrates as would have been expected. Over repeated evaluations, the procedure was demonstrated to have a maximum inherent variability of plus or minus one E-value.
\end{abstract}

Root substrates (substrates) are commonly used in the production of containerized greenhouse and nursery crops (Bunt, 1988; Nelson, 2003). Substrates are formulated from various inorganic and organic components such as peat, perlite, aged bark, rice hulls, various composts, and vermiculite to provide suitable physical and chemical properties as required by the specific crop and growing conditions (Bunt, 1988; Raviv and Lieth, 2008).

Among the most commonly evaluated and reported physical properties of substrates are bulk density, total pore space, air-filled pore space, and water-holding capacity. Bulk density refers to the weight of a given volume of substrate and is most commonly reported as grams of dry weight per $100 \mathrm{~cm}^{3}$ of substrate (Bunt, 1988; Wallach, 2008). Substrates with

\footnotetext{
Received for publication 8 Oct. 2010. Accepted for publication 26 Jan. 2011.

${ }^{1}$ Professor.

${ }^{2}$ Technical Specialist.

${ }^{3}$ To whom reprint requests should be addressed; e-mailmrevans@uark.edu.
}

low bulk densities are usually preferred because they facilitate handling and reduce shipping costs (Bunt, 1983; Wallach, 2008). However, a relatively high bulk density is desired when plant stability is an issue such as occurs with tall or top-heavy crops. Total pore space represents the volume of the substrate not occupied by substrate solids. Most greenhouse root substrates have a total pore space of $60 \%$ to $85 \%$ (Arnold Bik, 1983; Boertje, 1984; Jenkins and Jarrell, 1989). Air-filled pore space is the volume of the substrate that drains after a saturating irrigation. Air-filled pore space is important because it provides for gas exchange between the root environment and the atmosphere outside of the container. An air-filled pore space of $10 \%$ to $20 \%$ has commonly been recommended for substrates to be used to produce greenhouse crops (Jenkins and Jarrell, 1989).

Water-holding capacity, often referred to as container capacity, represents the volume of water retained by a substrate immediately after a saturating irrigation and drainage and is expressed as a percentage of total volume or weight of the substrate. A water-holding capacity of $45 \%$ to $65 \%(\mathrm{v} / \mathrm{v})$ has been commonly recommended for substrates for greenhouse crop production (Arnold Bik, 1983; Boertje, 1984; Jenkins and Jarrell, 1989).

The water-holding capacity of a substrate for greenhouse and nursery containers is further categorized as easily available, available, and unavailable water. The water held against tensions of 1 and $10 \mathrm{kPa}$ is defined as available water (Bunt, 1988; De Boodt and Verdonck, 1972). The water held against tension between 1 and $5 \mathrm{kPa}$ is defined as easily available water, and water held against tension higher than $10 \mathrm{kPa}$ is defined as the unavailable water (Ingram et al., 1993).

These methods of describing substrate water content have significant limitations. The term availability and the specific pressures are not universally agreed on. The tensions of 1,5 , and $10 \mathrm{kPa}$ are arbitrary and do not have physiological meaning across greenhouse and nursery crops. In fact, the limit of a tension of $10 \mathrm{kPa}$ was suggested by De Boodt and De Waele (1968) because it strongly inhibited Ficus growth; thus, the definition of water availability is species-specific. There is no exact tension at which water is unavailable to plants in general (Buamscha et al., 2007).

Water-holding capacity itself is a timespecific measurement that is limited to the status of the substrate immediately after saturation and drainage. It does not provide information regarding how quickly water is lost from the substrate, the substrate water status over time, or the irrigation frequency required for a substrate under specific conditions. Furthermore, in a given container size, water-holding capacity is a function of the volume and size of pores in a substrate. Large pores drain after irrigation and provide air-filled pore space, whereas small pores retain water after irrigation. However, the terms large pores and small pores are relative. Evaporation has been shown to account for $60 \%$ of the applied water lost from the substrate in the first 3 weeks after planting (Argo and Biernbaum, 2005). The rate at which water is lost from a substrate resulting from evaporation depends on several factors. Beardsell et al. (1979) demonstrated that as the pore size decreased, the tension with which water was held, increased, and thus as the pore size decreased, the resistance to evaporation increased. Therefore, water-holding capacity only accounted for whether a pore was small enough to retain water at container capacity. It did not take into account that the water being retained occurred in pores of different sizes that held water at different tensions. These different populations of water would evaporate at different rates as a result of the different pore sizes. Therefore, two substrates could theoretically have the same water-holding capacity but lose water to evaporation at different rates and the two substrates would dry at different rates. As an example, Beardsell et al. (1979) reported that peat had a higher water-holding capacity than pine bark or sawdust but peat lost water as a result of evaporation more rapidly than these two other organic components. The authors concluded that this was the result of 
the wicking effect of the peat fibers increasing the rate of evaporation. In addition to the specific pore sizes, other factors such as substrate color and thermal characteristics can affect the rate of water loss resulting from evaporation.

The frequency of irrigation depends on both the water-holding capacity as well as the rate of drying of the substrate. Water-holding capacity, the rate of drying, and how frequently a substrate must be irrigated all relate to what greenhouse managers and substrate manufacturers have generally referred to as a substrate's wetness. Greenhouse managers and substrate manufacturers have generally described substrate wetness by referring to a substrate as being a "dry" substrate or a "wet" substrate. Substrate wetness is an important characteristic because it affects the amount of water required to grow a crop, the irrigation frequency, and fertilization frequency if a liquid fertilization program is being used. Although the term substrate wetness is not a specific term for substrates in the scientific literature, it is one in which the horticultural industry is particularly interested and a measure of substrate wetness that accounts for each of these three variables would be a valuable tool.

The objectives of this research were to 1) develop a method of measuring substrate wetness that included the variables of water-holding capacity, drying rate, and irrigation frequency; 2) to create a single numeric value that could be used to describe the wetness of a substrate and allow comparisons of wetness among substrates; and 3) to determine if the procedure provided reasonable or expected values and what level of variation might be inherent in such a procedure.

\section{Materials and Methods}

Generation of E-values for various root substrates. The root substrates selected for the experiment were a Canadian sphagnum peatmoss (Fafard, Agawam, MA), super coarse perlite (Whittemore Company, Lawrence, MA), parboiled fresh rice hulls (Riceland Foods, Stuttgart, AR), LA 4 with fine peat (Sun Gro Horticulture, Bellevue, WA), Metro-Mix 360, SB 650, SB 200 (Sun Gro Horticulture, Bellevue, WA), and four substrates formulated by blending Canadian sphagnum peat (peat) with $20 \%$ and $30 \%(\mathrm{v} / \mathrm{v})$ super coarse perlite or $\mathrm{PBH}$. The substrates were placed into $53 \mathrm{~cm} \times$ $26 \mathrm{~cm} \times 5-\mathrm{cm}$ plastic flats and allowed to airdry at $32{ }^{\circ} \mathrm{C}$ until substrates no longer lost weight for a $24-\mathrm{h}$ period. Water was then added to the dry substrates to bring them to $50 \%$ moisture $(\mathrm{w} / \mathrm{w})$. The substrates were placed in sealed plastic bags and allowed to incubate for $48 \mathrm{~h}$ to reach moisture equilibrium.

The substrates were fluffed by tumbling in a plastic bag for $\approx 5$ seconds and placed into 15.2 -cm plastic containers $(10.3 \mathrm{~cm}$ lower diameter, $14.7 \mathrm{~cm}$ top diameter, $14.3 \mathrm{~cm}$ height, $1680 \mathrm{~mL}$ volume, $170 \mathrm{~cm}^{2}$ top surface area; ITML, Middlefield, OH). Containers were filled to the rim, tamped five times, and the excess root substrate removed by brushing. Containers were watered four times at $1-\mathrm{h}$ intervals with $650 \mathrm{~mL}$ of water. Additional substrate was added as needed after the first or second irrigation to allow for $1 \mathrm{~cm}$ of settling below the container rim. This resulted in 1500 $\mathrm{mL}$ of substrate and a exposed top substrate surface area of $161 \mathrm{~cm}^{2}$. After the final irrigation, the substrates were allowed to drain for $30 \mathrm{~min}$ to attain container capacity at which time they were weighed to obtain the total weight at container capacity. If any container with substrate varied from the other containers by more than $2 \mathrm{~g}$, it was discarded and a new container was filled with substrate and the process repeated.

Three containers of each root substrate were placed randomly into the center of a $117 \mathrm{~cm}$ high $\times 185 \mathrm{~cm}$ wide $\times 76-\mathrm{cm}$ deep growth chamber (Conviron E15; Winnipeg, Manitoba, Canada). Growth chamber temperature was maintained at $21 \pm 0.4{ }^{\circ} \mathrm{C}$. Photosynthetic photon flux density was maintained at $464 \pm$ $27 \mu \mathrm{mol} \cdot \mathrm{m}^{-2} \cdot \mathrm{s}^{-1}$ at container level using a combination of cool white fluorescent and incandescent lamps. The air velocity at the container rim level was $0.30 \pm 0.05 \mathrm{~m} \cdot \mathrm{s}^{-1}$ and the air flow was $0.42 \pm 0.05 \mathrm{~m}^{3} \cdot \mathrm{min}^{-1}$ with air being circulated from the floor of the chamber and around the base of the containers. The relative humidity was maintained at $60 \% \pm 2 \%$.

The containers were weighed daily at $1100 \mathrm{HR}$ and weights were recorded. Plants were placed back in their original locations within the chamber after weighing. The days required for the substrates to reach the $10 \%$ (v/v) moisture level (or first day to immediately decrease to below $10 \%$ ) were recorded. The $10 \%$ moisture level was determined from the known weights of the dry substrate and the container. After substrates reached the $10 \%$ moisture level, the containers with substrate were oven-dried at $60{ }^{\circ} \mathrm{C}$ for $72 \mathrm{~h}$. Afterward, the containers and dry substrate were weighed and these weights subtracted from the original daily weights to determine the water weight in

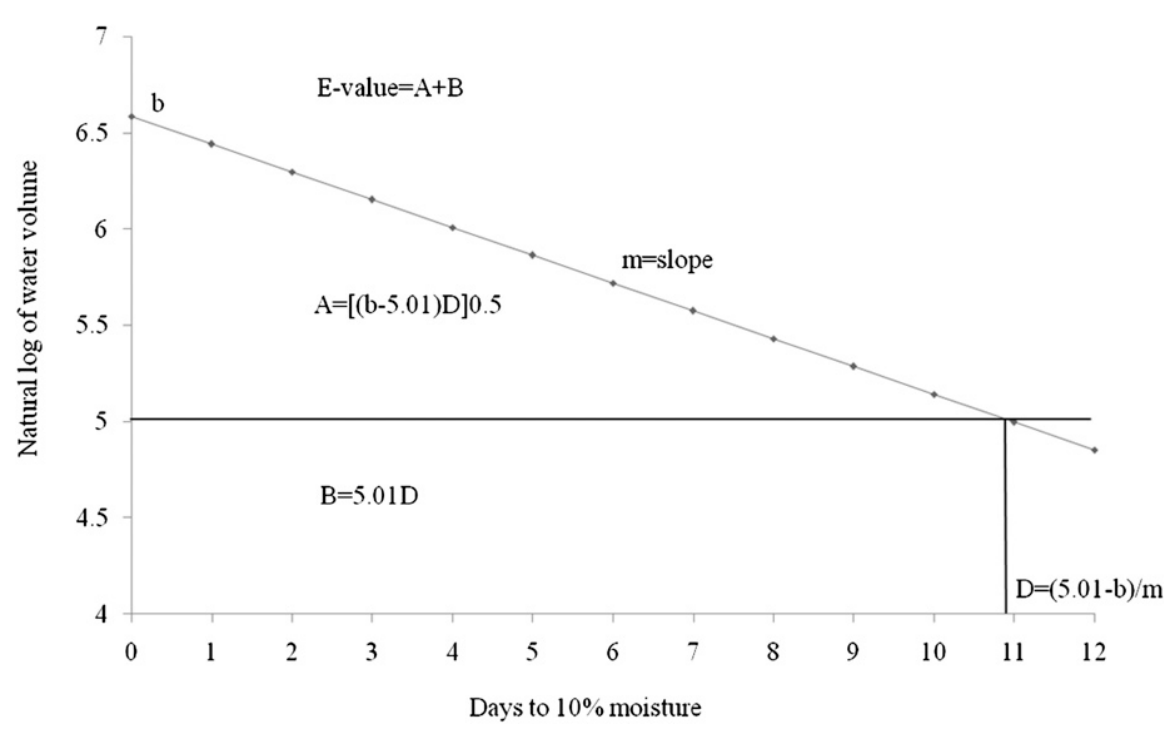

Fig. 1. Example of a regression line used to calculate an E-value where the E-value was the area under the regression line and was calculated as $\mathrm{E}=[(\mathrm{b}-5.01) \mathrm{D}] 0.5+5.01 \mathrm{D}$ where $\mathrm{D}$ was the number of days to return to $10 \%$ moisture and $\mathrm{b}$ was the intercept of the regression line. The value of 5.01 was a constant derived from the natural $\log$ of volume of water $(150 \mathrm{~mL})$ contained in the substrate at $10 \%$ moisture specific to the volume of the container used in these experiments. 
interval was generated for the intercepts and slopes of each regression line to determine if there were significant differences among these values for each run. The differences in days to $10 \%$ moisture and the generated E-values were determined by generating these values for the $95 \%$ confidence intervals for the intercepts and slopes for each substrate.

\section{Results}

Generation of E-values for various root substrates. The regression lines generated from the transformed water volumes displayed three factors related to the wetness of the substrates (Fig. 2). The y intercept was a relative measure of the water-holding capacity of the substrate at container capacity. The slope of the line was the rate of drying, whereas the length of the line represented the number of days required to reach $10 \%$ moisture and, depending on cultural practices, a relative measure of the inverse of the required irrigation frequency.

The PBH had a lower intercept (waterholding capacity) than perlite both of which had lower intercepts than all other substrates (Table 1). Adding $30 \%$ perlite or $20 \%$ and $30 \%$ PBH reduced the intercept of the peat. Increasing the amount of either PBH or perlite in the peat-based substrates decreased the intercept of the substrates and PBH-containing substrates had a lower intercept than equivalent perlite-containing substrates. The LA 4 substrate had the highest intercept of the commercial substrates followed by SB200, Metro-Mix 360, and SB 650, respectively.

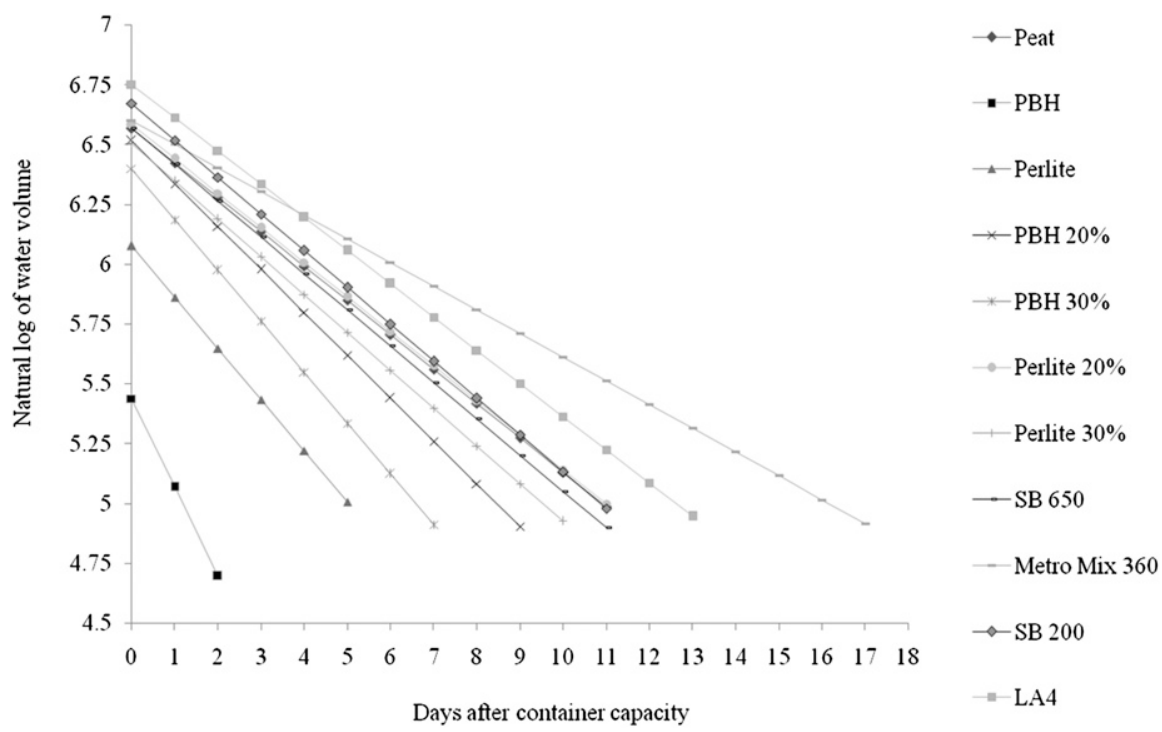

Fig. 2. Regression equations for root substrates. Equations for each substrate were: peat, $\mathrm{y}=6.57-0.14 \mathrm{x}\left(R^{2}=\right.$ $0.99) ; \mathrm{PBH}, \mathrm{y}=5.43-0.37 \mathrm{x}\left(R^{2}=0.92\right) ;$ perlite, $\mathrm{y}=6.08-0.21 \mathrm{x}\left(R^{2}=0.98\right) ; \mathrm{PBH} 20 \%, \mathrm{y}=6.52-0.18 \mathrm{x}$ $\left(R^{2}=0.99\right)$; PBH $30 \%, \mathrm{y}=6.40-0.21 \mathrm{x}\left(R^{2}=0.98\right)$; perlite $20 \%, \mathrm{y}=6.59-0.14 \mathrm{x}\left(R^{2}=0.99\right)$; perlite $30 \%$, $\mathrm{y}=6.50-0.16 \mathrm{x}\left(R^{2}=0.99\right) ; \mathrm{SB} 650, \mathrm{y}=6.57-0.15\left(R^{2}=0.99\right) ;$ Metro Mix $360, \mathrm{y}=6.60-0.10 \mathrm{x}\left(R^{2}=0.96\right)$ $\mathrm{SB} 200, \mathrm{y}=6.67-0.15 \mathrm{x}\left(R^{2}=0.99\right)$; and LA4, $\mathrm{y}=6.75-0.14 \mathrm{x}\left(R^{2}=0.99\right) . \mathrm{PBH}=$ parboiled fresh rice hulls.

Table 1. Regression model values and days to $10 \%$ moisture with $95 \%$ confidence intervals for various root substrates.

\begin{tabular}{|c|c|c|c|c|c|c|}
\hline Substrate ${ }^{z}$ & Intercept & $\begin{array}{c}\text { Intercept } 95 \% \\
\text { confidence } \\
\text { interval }\end{array}$ & Slope $\mathrm{y}^{\mathrm{y}}$ & $\begin{array}{l}\text { Slope } 95 \% \\
\text { confidence } \\
\text { interval }^{\mathrm{y}}\end{array}$ & $\begin{array}{c}\text { Days } \\
\text { to } 10 \% \\
\text { moisture }^{\mathrm{x}}\end{array}$ & $\begin{array}{c}\text { Days to } 10 \% \\
\text { moisture } 95 \% \\
\text { confidence interval }\end{array}$ \\
\hline Sphagnum peat & 6.57 & $6.53-6.61$ & 0.14 & $0.14-0.15$ & 10.8 & $10.7-10.9$ \\
\hline $\mathrm{PBH}$ & 5.43 & $5.24-5.64$ & 0.37 & $0.20-0.45$ & 1.2 & $1.1-1.4$ \\
\hline Perlite & 6.08 & $6.02-6.13$ & 0.21 & $0.20-0.23$ & 5.0 & $4.9-5.1$ \\
\hline $\begin{array}{l}\text { PBH } 20 \%+\text { sphagnum } \\
\text { peat } 80 \%\end{array}$ & 6.52 & $6.49-6.54$ & 0.18 & $0.17-0.18$ & 8.4 & $8.3-8.5$ \\
\hline $\begin{array}{l}\text { PBH } 30 \%+\text { sphagnum } \\
\text { peat } 70 \%\end{array}$ & 6.40 & $6.35-6.45$ & 0.21 & $0.20-0.23$ & 6.5 & $6.4-6.7$ \\
\hline $\begin{array}{l}\text { Perlite } 20 \%+\text { sphagnum } \\
\text { peat } 80 \%\end{array}$ & 6.59 & $6.55-6.62$ & 0.14 & $0.14-0.15$ & 10.9 & $10.8-11.0$ \\
\hline $\begin{array}{l}\text { Perlite } 30 \%+\text { sphagnum } \\
\text { peat } 70 \%\end{array}$ & 6.50 & $6.48-6.58$ & 0.16 & $0.15-0.16$ & 9.5 & $9.3-9.7$ \\
\hline SB 650 & 6.57 & $6.54-6.59$ & 0.15 & $0.15-0.16$ & 10.3 & $10.2-10.4$ \\
\hline Metro-Mix 360 & 6.60 & $6.55-6.66$ & 0.10 & $0.09-0.10$ & 16.0 & $15.8-16.3$ \\
\hline SB 200 & 6.67 & $6.64-6.70$ & 0.15 & $0.15-0.16$ & 10.8 & $10.7-10.9$ \\
\hline LA 4 & 6.75 & $6.71-6.79$ & 0.14 & $0.13-0.14$ & 12.5 & $12.4-12.7$ \\
\hline
\end{tabular}

${ }^{\mathrm{z}} \mathrm{PBH}=$ parboiled fresh rice hulls (Riceland Foods, Stuttgart, AR). Perlite was a medium course grade (Whittemore Company, Lawerence, MA). Sphagnum peat was supplied by Fafard (Agawam, MA) and the SB 650, Metro Mix 360, SB 200, and LA 4 substrates were supplied by Sun Gro Horticulture (Bellevue, WA). ${ }^{\mathrm{y}}$ All slope values were negative.

${ }^{\mathrm{x}}$ Days to $10 \%$ moisture reported were determined using the regression equations.
The PBH had a higher mean slope (faster drying rate) than perlite but the slope confidence intervals of these substrates overlapped (Table 1). Adding $20 \%$ or $30 \% \mathrm{PBH}$ and $30 \%$ perlite to peat increased the slope of the substrates. Increasing the amount of PBH or perlite from $20 \%$ to $30 \%$ also increased the slope of the resulting substrate, and $\mathrm{PBH}$-containing substrates had a higher slope than equivalent perlite-containing substrates. The SB 200 and SB 650 substrates had the highest slope of the commercial substrates followed by LA 4 and Metro-Mix 360, respectively. Across all substrates, the MM 360 had the lowest slope.

The $\mathrm{PBH}$ required fewer days to reach $10 \%$ moisture than perlite, both of which required fewer days than all other substrates (Table 1). Adding $20 \%$ or $30 \% \mathrm{PBH}$ or $30 \%$ perlite to peat decreased the days required to reach $10 \%$ moisture. Increasing the amount of either PBH or perlite in the peat-based substrates from $20 \%$ to $30 \%$ decreased the days to $10 \%$ moisture and $\mathrm{PBH}-$ containing substrates required fewer days to reach $10 \%$ moisture than equivalent perlitecontaining substrates. Of the commercial substrates, SB 650 required the fewest days to reach $10 \%$ moisture followed by SB 200, LA 4, and Metro-Mix 360, respectively.

When E-values were calculated as the area under the line for each substrate, PBH had a lower E-value than perlite, both of which had a lower E-value than all other substrates (Table 2 ). The addition of $20 \%$ or $30 \% \mathrm{PBH}$ or $30 \%$ perlite to peat lowered the E-value of the

Table 2. E-values and 95\% confidence intervals generated for various root substrates.

\begin{tabular}{lcc}
\hline & $\begin{array}{c}\text { E-value 95\% } \\
\text { confidence } \\
\text { interval }^{\mathrm{x}}\end{array}$ \\
Substrate $^{\mathrm{z}}$ & 63 & $62-63$ \\
Ephagnum peat & 6 & $6-8$ \\
PBH & 28 & $27-28$ \\
$\begin{array}{l}\text { Perlite } \\
\text { PBH 20\%+ sphagnum }\end{array}$ & 48 & $48-49$ \\
$\quad$ peat 80\% & & \\
PBH 30\%+ sphagnum & 37 & $36-38$ \\
$\quad$ peat 70\% & & \\
Perlite 20\%+ sphagnum & 63 & $62-64$ \\
$\quad$ peat 80\% & & \\
Perlite 30\%+ sphagnum & 54 & $54-56$ \\
$\quad$ peat 70\% & 59 & $59-60$ \\
SB 650 & 93 & $92-94$ \\
Metro-Mix 360 & 63 & $62-64$ \\
SB 200 & 74 & $73-75$ \\
LA 4
\end{tabular}

${ }^{\text {zPBH }}=$ parboiled fresh rice hulls (Riceland Foods, Stuttgart, AR). Sphagnum peat was supplied by Fafard (Agawam, MA) and the SB 650, Metro-Mix 360 , SB 200, and LA 4 substrates were supplied by Sun Gro Horticulture (Bellevue, WA).

${ }^{\mathrm{y}} \mathrm{E}$-values generated as the area under the line produced by regressing the natural $\log$ of the water volume over time for the number of days required for the substrate to reach $10 \%$ moisture $(\mathrm{v} / \mathrm{v})$ content as described by the equation $\mathrm{E}=[(\mathrm{b}-5.01) \mathrm{D}] 0.5+5.01 \mathrm{D}$ where $\mathrm{D}$ was the number of days to return to $10 \%$ moisture and $\mathrm{b}$ was the intercept of the regression line. E-values had the units $\ln (\mathrm{mL}) \times$ days. However, the units had no practical or demonstrative value and E-values are thus reported as whole numbers without units.

${ }^{\mathrm{x}}$ Confidence intervals are E-values generated using the $95 \%$ confidence intervals for the regression equation variables and rounded to the nearest whole number. 
resulting substrate as compared with $100 \%$ peat. As the amount of $\mathrm{PBH}$ or perlite added to peat was increased, the E-value decreased. Furthermore, peat substrates containing PBH had lower E-values than peat-based substrates containing equivalent amounts of perlite. Of the commercial substrates, Metro-Mix 360 had the highest E-value followed by LA 4, SB 200, and SB 650, respectively.

Determination of degree of variability of E-values generated for root substrates. The regression equation intercept for the $30 \% \mathrm{PBH}$ substrate was 6.4 for the five runs (Table 3). The regression equation intercept for the SB 650 substrate was 6.57 for the five runs. For both substrates, the intercepts for each of the runs were within the $95 \%$ confidence intervals of the other runs.

The regression equation slope for the $30 \%$ PBH substrate was -0.21 for the five runs (Table 3). The regression equation slope for the SB 650 substrate was -0.15 for the five runs. For both substrates, all slope values were within the $95 \%$ confidence interval of one another.

The days to $10 \%$ moisture for the $30 \% \mathrm{PBH}$ substrate ranged from 6.5 to 6.6 among the five runs (Table 3 ). The days to $10 \%$ moisture for the SB 650 substrate ranged from 10.2 to 10.3 among the five runs. For both substrates, the days to $10 \%$ moisture for each of the runs were within the $95 \%$ confidence intervals of the other runs.

The E-values generated from the regression equations for the $30 \% \mathrm{PBH}$ substrate ranged from 37.2 to 37.4 (Table 4). The E-values generated from the regression equations for the SB 650 substrate ranged from 59.2 to 59.5 . For both substrates, the E-values for each of the runs were less than a single whole number and were within the $95 \%$ confidence intervals of the other runs.

\section{Discussion}

Because this procedure is used to create a novel variable describing substrates, it is not possible to directly evaluate the accuracy of the procedure nor to directly relate the E-values produced to other data related to a given substrate. However, we can examine the E-values produced and indirectly relate them to what is known about the substrates through other published research and experience.

The described procedure produced Evalues that ranked the substrates as would have been expected based on previous research and industry experience. Perlite and $\mathrm{PBH}$ had the lowest E-values of all of the substrates evaluated. Furthermore, PBH had a lower E- value than perlite. These values were expected because perlite and PBH have been shown to have low water-holding capacities and to dry rapidly after irrigation (Evans and Gachukia, 2007). Additionally, PBH is commonly added to substrates to increase air-filled pore space, reduce water-holding capacity, and increase drying rate.

When PBH was added to peat at either $20 \%$ or $30 \%$, the E-value was reduced. Adding $\mathrm{PBH}$ to peat at $30 \%$ resulted in a lower Evalue than when added at $20 \%$. Researchers

Table 3. Regression model values and days to $10 \%$ moisture with $95 \%$ confidence intervals for repeated runs of two root substrates.

\begin{tabular}{|c|c|c|c|c|c|c|c|}
\hline Substrate $^{z}$ & Run & Intercept & $\begin{array}{l}\text { Intercept } 95 \% \\
\text { confidence } \\
\text { interval } \\
\end{array}$ & Slope $^{y}$ & $\begin{array}{l}\text { Slop } 95 \% \\
\text { confidence }^{\text {interval }} \\
\end{array}$ & $\begin{array}{l}\text { Days to } 10 \% \\
\text { moisture }^{\mathrm{x}}\end{array}$ & $\begin{array}{c}\text { Days to } 10 \% \\
\text { moisture } 95 \% \\
\text { confidence interval }\end{array}$ \\
\hline $30 \% \mathrm{PBH}$ & 1 & 6.40 & $6.35-6.45$ & 0.21 & $0.20-0.22$ & 6.5 & $6.4-6.7$ \\
\hline $30 \% \mathrm{PBH}$ & 2 & 6.40 & $6.36-6.44$ & 0.21 & $0.20-0.22$ & 6.5 & $6.5-6.6$ \\
\hline $30 \% \mathrm{PBH}$ & 3 & 6.40 & $6.36-6.43$ & 0.21 & $0.20-0.22$ & 6.5 & $6.4-6.7$ \\
\hline $30 \% \mathrm{PBH}$ & 4 & 6.40 & $6.36-6.44$ & 0.21 & $0.20-0.22$ & 6.6 & $6.5-6.6$ \\
\hline $30 \% \mathrm{PBH}$ & 5 & 6.40 & $6.36-6.44$ & 0.21 & $0.20-0.22$ & 6.5 & $6.4-6.6$ \\
\hline SB 650 & 1 & 6.57 & $6.54-6.59$ & 0.15 & $0.14-0.16$ & 10.3 & $10.2-10.4$ \\
\hline SB 650 & 2 & 6.57 & $6.52-6.62$ & 0.15 & $0.14-0.16$ & 10.3 & $10.1-10.4$ \\
\hline SB 650 & 3 & 6.57 & $6.53-6.60$ & 0.15 & $0.15-0.16$ & 10.2 & $10.1-10.3$ \\
\hline SB 650 & 4 & 6.57 & $6.53-6.61$ & 0.15 & $0.15-0.16$ & 10.2 & $10.1-10.4$ \\
\hline SB 650 & 5 & 6.57 & $6.54-6.63$ & 0.15 & $0.14-0.15$ & 10.3 & $10.2-10.4$ \\
\hline
\end{tabular}

${ }^{2} \mathrm{PBH}=$ parboiled fresh rice hulls (Riceland Foods, Stuttgart, AR). Sphagnum peat was supplied by Fafard (Agawam, MA) and the SB 650 substrate was supplied by Sun Gro Horticulture (Bellevue, WA).

${ }^{y}$ All slope values were negative.

${ }^{\mathrm{x}}$ Days to $10 \%$ moisture reported were determined using the regression equations.

have demonstrated that as the amount of PBH in a peat-based substrate was increased from $20 \%$ to $30 \%$, the water-holding capacity decreased exponentially (Evans and Gachukia, 2007). When perlite was added to peat at $20 \%$, there was no difference in the E-value. However, when perlite was added to the peat at $30 \%$, the E-value was reduced. This concurs with previous research in which it was demonstrated that adding perlite up to $20 \%$ had little effect on the physical properties of the substrate (Evans and Gachukia, 2007). However, adding $30 \%$ perlite reduced water-holding capacity of the substrate. Furthermore, it was shown that equivalent amounts of PBH resulted in a substrate with a lower water-holding capacity, a higher air-filled pore space, and a higher drying rate than sphagnum peat-based substrates containing equivalent amounts of perlite (Evans and Gachukia, 2007). Therefore, the E-values generated for these substrates were as would have been expected and ranked the substrates as would have been expected based on previous research and experience.

In each case, the procedure produced Evalues that ranked the commercial substrates as would have been expected based on previous research and industry experience. Of the four commercial substrates evaluated, MetroMix 360 had the highest E-value. This substrate was composed of sphagnum peat, vermiculite, fine composted pine bark, and bark ash. It is described as being suitable where a higher water-holding capacity (Sun Gro, 2010) is desired and is known in the industry to have a high water-holding capacity and a very slow drying rate (Rick Vetanovetz, Sun Gro Horticulture, personal communication). The SB 200 substrate contained composted pine bark, sphagnum peat, and coarse perlite. The SB 650 substrate was composed of the same components but with different proportions so that, as noted in the manufacturer's literature, it was designed to have a higher amount of drainage (Sun Gro, 2010). Therefore, as would have been expected, SB 650 had an E-value that was 4 points lower than the SB 200 substrate. The LA 4 substrate used in this study was composed of a fine-textured peat and therefore would have been expected to have a high water-holding
Table 4. E-values and 95\% confidence intervals generated for repeated determinations of $\mathrm{E}$ values of two root substrates.

\begin{tabular}{|c|c|c|c|}
\hline Substrate $^{z}$ & Run & E-value ${ }^{y}$ & $\begin{array}{c}\text { E-value } 95 \% \\
\text { confidence } \\
\text { interval }^{\mathrm{x}}\end{array}$ \\
\hline$\overline{30 \% \mathrm{PBH}}$ & 1 & 37.2 & $37.1-37.4$ \\
\hline $30 \% \mathrm{PBH}$ & 2 & 37.3 & $37.2-37.4$ \\
\hline $30 \% \mathrm{PBH}$ & 3 & 37.3 & $36.8-37.9$ \\
\hline $30 \% \mathrm{PBH}$ & 4 & 37.4 & $37.1-37.7$ \\
\hline $30 \% \mathrm{PBH}$ & 5 & 37.2 & $37.0-37.4$ \\
\hline SB 650 & 1 & 59.4 & $58.8-60.0$ \\
\hline SB 650 & 2 & 59.4 & $58.9-60.1$ \\
\hline SB 650 & 3 & 59.3 & $58.9-59.8$ \\
\hline SB 650 & 4 & 59.2 & $58.6-60.1$ \\
\hline SB 650 & 5 & 59.5 & $59.4-60.4$ \\
\hline
\end{tabular}

${ }^{2} \mathrm{PBH}=$ parboiled fresh rice hulls (Riceland Foods, Stuttgart, AR). Sphagnum peat was supplied by Fafard (Agawam, MA) and the SB 650 substrate was supplied by Sun Gro Horticulture (Bellevue, WA).

${ }^{ } \mathrm{E}$-values generated as the area under the line produced by regressing the natural log of the water volume over time for the number of days required for the substrate to reach $10 \%$ moisture $(\mathrm{v} / \mathrm{v})$ content as described by the equation $\mathrm{E}=[(\mathrm{b}-$ $5.01) \mathrm{D}] 0.5+5.01 \mathrm{D}$ where $\mathrm{D}$ was the number of days to return to $10 \%$ moisture and $\mathrm{b}$ was the intercept of the regression line. E-values had the units $\ln (\mathrm{mL}) \times$ days. However, the units had no practical or demonstrative value and E-values are thus reported as whole numbers without units. ${ }^{\mathrm{x}}$ Confidence intervals are E-values generated using the $95 \%$ confidence intervals for the regression equation variables and rounded to the nearest whole number.

capacity and to dry more slowly than SB 200 and SB 650 .

Argo and Biernbaum (2005) reported that $60 \%$ of the water applied to a substrate was lost through evaporation during the first 3 weeks after potting, and Beardsell et al. (1979) demonstrated that substrates lost water to evaporation at different rates. The dry-down lines generated in this research demonstrated the different rates of water loss among the substrates. The initial water-holding capacity and the rate of drying resulted in different numbers of days required to reach $10 \%$ moisture (different lengths on lines). If only the intercepts had been used to describe the substrate wetness and drying rate had been ignored, the substrates would have been ranked in different orders than when ranked using the E-values. For example, MM 
360 was selected specifically because it was known to be one of the wettest substrates used in the greenhouse industry. However, based only on the intercepts, MM 360 would have been ranked as a dryer substrate than LA 4 and SB 200. Peat would have had the same wetness as SB 650, which had bark and perlite added specifically to create a dryer substrate. The $20 \%$ perlite substrate would have had a higher wetness than peat although from previous research, a $20 \%$ perlite and $80 \%$ sphagnum peat substrate has been shown to have similar properties as $100 \%$ sphagnum peat. The $20 \% \mathrm{PBH}$ substrate and $30 \%$ perlite substrates had intercepts that were not significantly different. However, the $20 \%$ PBH substrate dried at a quicker rate and therefore had a lower E-value than the $30 \%$ perlite.

Another way to visualize this is to look at cases (Fig. 2) in which regression lines of substrates crossed one another. For example, the MM 360 did not have the highest waterholding capacity (intercept) but because it dried very slowly, it had a lower slope and over time the line for MM 360 crossed the lines for LA 4 and SB 200. This resulted in MM 360 having a higher E-value than either LA4 or SB 200 although it had a lower initial water-holding capacity. Using intercepts rather than E-values to characterize wetness in this case alone would have resulted in two of the 11 substrates tested being incorrectly ranked against in perspective to MM 360

When E-values were repeatedly determined for both substrates, the intercepts, the slopes, and the days to $10 \%$ moisture for each run were within the $95 \%$ confidence interval of one another and were therefore not different among the runs. Because E-values are designed to be reported as whole numbers, the E-values generated for $30 \% \mathrm{PBH}$ were 37 for all runs and the E-values for SB 650 were 59 or 60 . When rounded to a whole number, the $95 \%$ confidence intervals across all runs for $30 \%$ PBH and SB 650 ranged from 37 to 38 and 59 to 60 , respectively. With this level of variation, E-values generated over repeated runs would be expected to vary by no more than one Evalue unit. Because the E-values of substrates in this study ranged from 6 to 93, the level of variation observed for a specific substrate would have little practical importance.

E-values represent a potentially significant new tool for use by greenhouse and nursery managers and substrate manufacturers. Managers may choose to select substrates based on their E-values. When a manager desires a substrate that requires less frequent irrigation, they can select a substrate with a higher E-value. Likewise, when a manager desires a substrate that dries more quickly, they can select a substrate with a lower E-value. If managers are accustomed to a substrate composed of specific components and would choose to use a similar substrate but with an increased or decreased drying rate, they could use the Evalues as a way to adjust one or more of the substrate components until the desired E-value is achieved.

In a similar manner, substrate manufacturers could design substrates to have specific Evalues rather than designing substrates to contain certain percentages of components. In fact, a substrate manufacturer might choose to have a series of substrates such as a bark and peat series or a perlite and peat series and change the proportion of the components to generate a desired E-value. The substrate industry could also use E-values as a quality control tool to evaluate how uniformly and consistently they are producing a substrate. Individual substrate components could be evaluated before their use to determine if they have an appropriate E-value or if the E-value is different from what would be expected. Adjustments could be made before substrate mixing to achieve the desired E-value. For example, if sphagnum peat that is to be used in a substrate is coarser or finer than normal and is behaving differently than in previous years, this could be determined before mixing and changes made in the formulation to achieve the desired E-value of the final substrate. The greenhouse or nursery manager would be receiving a substrate that, although had different proportions of components, would behave in a greenhouse environment with respect to its water-holding capacity, its drying rate, and its irrigation frequency in a consistent manner to what the manager had experienced previously.

\section{Literature Cited}

Argo, W.R. and J.A. Biernbaum. 2005. The effect of irrigation method, water-soluble fertilization, preplant nutrient charge, and surface evaporation on early vegetative and root growth of poinsettia. J. Amer. Soc. Hort. Sci. 120:163-169.

Arnold Bik, R. 1983. Substrates in floriculture. Proc. XXI Intl. Hort Congr. 2:811-822.

Beardsell, D.V., D.G. Nichols, and D.L. Jones. 1979. Water relations of nursery potting media. Sci. Hort. 11:9-17.

Boertje, G.A. 1984. Physical laboratory analyses of potting composts. Acta Hort. 150:47-50.

Buamscha, M.G., J.E. Altland, D.M. Sullivan, D.A. Horneck, and J. Cassidy. 2007. Chemical and physical properties of douglas fir bark relevant to the production of container plants. HortScience 42:1281-1286.

Bunt, A.C. 1983. Physical properties of mixtures of peat and minerals of different particle size and bulk density for potting substrates. Acta Hort. 150:143-153.

Bunt, A.C. 1988. Media and mixes for container grown plants. Unwin Hyman, Ltd., London, UK

De Boodt, M. and N. DeWaele. 1968. Study on the physical properties of artificial soils and the growth of ornamental plants. Pedologie (Gent) 18:275-300.

De Boodt, M. and O. Verdonck. 1972. The physical properties of the substrates in horticulture. Acta Hort. 26:37-44.

Evans, M.R. and M.M. Gachukia. 2007. Physical properties of sphagnum peat-based root substrates amended with perlite or parboiled fresh rice hulls. HortTechnology 17:312-315.

Ingram, R.E., R.W. Henley, and T.H. Yeager 1993. Growth media for container plants Florida Coop. Ext. Serv. Univ. of Florida. Bul. 24.

Jenkins, J.R. and W.M. Jarrell. 1989. Predicting physical and chemical properties of container mixtures. HortScience 24:292-295.

Nelson, P.V. 2003. Greenhouse operation and management. 6th Ed. Prentice Hall, Upper Saddle River, NJ.

Raviv, M. and J.H. Lieth. 2008. Soilless culture: Theory and practice. Elsevier, Maryland Heights, MO

Sun Gro. 2010. Professional growing products catalog. Bellevue, WA, 2 Oct. 2010. $<$ http://sungro com/2009_Catalog.pdf>. Apr. 2010.

Wallach, R. 2008. Physical characteristics of soilless media, p. 41-116. In: Raviv, M. and J.H. Lieth (eds.). Soilless culture: Theory and practice. Elsevier B.V., New York, NY 